\title{
Repeated electroconvulsive seizure induces c-Myc down-regulation and Bad inactivation in the rat frontal cortex
}

\author{
Won Je Jeon ${ }^{1 *}$, Se Hyun Kim ${ }^{1,2 *}$, Myoung Suk Seo ${ }^{1}$, \\ Yeni Kim ${ }^{3}$, Ung Gu Kang ${ }^{2,4}$, Yong-Sung Juhnn ${ }^{5}$ \\ and Yong Sik Kim $2,4,6$ \\ ${ }^{1}$ Clinical Research Institute \\ Seoul National University Hospital \\ Seoul 110-744, Korea \\ ${ }^{2}$ Department of Psychiatry and Behavioral Science \\ ${ }^{3}$ Department of Child and Adolescent Psychiatry \\ ${ }^{4}$ Institute of Human Behavioral Medicine \\ ${ }^{5}$ Department of Biochemistry and Molecular Biology \\ Seoul National University College of Medicine \\ Seoul, 110-744 Korea \\ ${ }^{6}$ Corresponding author: Tel, 82-2-2072-2204; \\ Fax, 82-2-744-7241; E-mail, kys @ snu.ac.kr \\ *These authors contributed equally to this work. \\ DOI 10.3858/emm.2008.40.4.435
}

\section{Accepted 25 April 2008}

Abbreviations: AKAP, A kinase anchoring protein; BDNF, brainderived neurotrophic factor; DAPI, 4',6'-diamidino-2-phenylindole; $E C S$, electroconvulsive seizure; ECT, electroconvulsive therapy; FGF, fibroblast growth factor; GFAP, glial fibrillary acidic protein; Neu-N, neuronal nuclear protein; PARP, poly(ADP-ribose) polymerase; RSK, ribosomal s6 kinase; $S$, sham

\begin{abstract}
Repeated electroconvulsive seizure (ECS), a model for electroconvulsive therapy (ECT), exerts neuroprotective and proliferative effects in the brain. This trophic action of ECS requires inhibition of apoptotic activity, in addition to activation of survival signals. c-Myc plays an important role in apoptosis of neurons, in cooperation with the Bcl-2 family proteins, and its activity and stability are regulated by phosphorylation and ubiquitination. We examined c-Myc and related proteins responsible for apoptosis after repeated ECS. In the rat frontal cortex, repeated ECS for 10 days reduced the total amount of c-Myc, while increasing phosphorylation of c-Myc at Thr58, which reportedly induces degradation of c-Myc. As expected, ubiquitination of both phosphorylated and total c-Myc increased after 10 days ECS, suggesting that ECS may reduce c-Myc protein level via ubiquitination-proteasomal degradation. Bcl-2 family proteins, caspase,
\end{abstract}

and poly(ADP-ribose) polymerase (PARP) were investigated to determine the consequence of down-regulating c-Myc. Protein levels of Bcl-2, Bcl- $\mathrm{X}_{\mathrm{L}}, \mathrm{Bax}$, and Bad showed no change, and cleavage of caspase-3 and PARP were not induced. However, phosphorylation of Bad at Ser-155 and binding of Bad to 14-3-3 increased without binding to $\mathrm{Bcl}-\mathrm{X}_{\mathrm{L}}$ after repeated ECS, implying that repeated ECS sequesters apoptotic $B a d$ and frees pro-survival Bcl- $\mathrm{L}_{\mathrm{L}}$. Taken together, C-Myc down-regulation via ubiquitination-proteasomal degradation and Bad inactivation by binding to 14-3-3 may be anti-apoptotic mechanisms elicited by repeated ECS in the rat frontal cortex. This finding further supports the trophic effect of ECS blocking apoptosis as a possible therapeutic effect of ECT.

Keywords: apoptosis; bcl-2-associated $\mathrm{X}$ protein; electroconvulsive therapy; nerve growth factors; proto-oncogene proteins c-bcl-2; proto-oncogene proteins c-myc; ubiquitination

\section{Introduction}

Electroconvulsive therapy (ECT) is effective for treating mood disorder and schizophrenia, but the molecular basis for its beneficial effects remains unknown. The therapeutic effect of ECT requires multiple administrations, and repeated electroconvulsive seizure (ECS), an animal model for ECT, exerts trophic activity, including neuroprotective and proliferative effects, in the brain. ECS may prevent neuronal apoptosis induced by kainic acid (Kondratyev et al., 2001), decrease neuronal death (Busnello et al., 2006), and counteract corticosteroneinduced inhibition of neurogenesis and gliogenesis (Hellsten et al., 2002; Wennstrom et al., 2006). The majority of reports have focused on the hippocampus regarding the trophic effects of ECS (Hellsten et al., 2002; Wennstrom et al., 2006). However, Madsen et al. (2005) demonstrated glial cell proliferation in the rat frontal cortex after repeated ECS, and we reported that repeated ECS activates proliferative signals in the rat frontal cortex, such as the Cdk2-pRB-E2F1 cell cycle pathway and ERK pathway (Kim et al., 2005; Kang et al., 2006).

This trophic action of ECS is associated with the activation of intracellular survival signal pathways. Expression of brain-derived neurotrophic factor 
(BDNF), VEGF, and fibroblast growth factor (FGF) is up-regulated by ECS (Nibuya et al., 1995; Kondratyev et al., 2001; Newton et al., 2003), and ECS affects pro-survival signals related to ERK, PKA, and Akt (Kang et al., 1994, 2004, 2006; Altar et al., 2004). Survival and proliferation of neural cells require not only activation of survival signals, but also inhibition of apoptotic signaling activity (Raff et al., 1993). Therefore, ECS may affect apoptotic signals to block cell death, in addition to having positive effects on survival signals.

c-Myc has been suggested as an important regulator of not only cell proliferation, cell cycle progression, and differentiation, but also apoptosis (Nilsson and Cleveland, 2003). In post-mitotic neurons, c-Myc plays a critical role in promoting apoptosis in response to various stimuli (McGahan et al., 1998; Qin et al., 1999; Nakai et al., 2000). In addition, c-Myc may contribute to the pathogenesis of schizophrenia and bipolar disorder (Benes et al., 2006; Jarskog, 2006), and c-Myc expression increases in mouse cortex after methamphetamine administration (Thiriet et al., 2001), which induces schizophrenic manifestations in animals (Akiyama et al., 1994). Accordingly, c-Myc may be involved in the pathophysiology of psychiatric disorders, therapeutic indications of ECT, implying that c-Myc can be a valuable candidate molecule for studying the effect of ECS on apoptotic signals.

Posttranslational modification of c-Myc affects its activity by controlling protein stability. Thr58 and Ser62 residues in c-Myc, controlled by Ras pathways, are important in determining the stability of c-Myc (Yeh et al., 2004). Phosphorylation of c-Myc at Ser62 stabilizes c-Myc, but phosphorylation at Thr58 destabilizes c-Myc, which is mediated by the ubiquitination-proteasomal degradation process (Pulverer et al., 1994; Gregory et al., 2003; Yeh et al., 2004; Vervoorts et al., 2006).

The $\mathrm{Bcl}-2$ family of proteins comprises important effectors and regulators of c-Myc for triggering apoptosis (Nilsson and Cleveland, 2003). The Bcl-2 family of proteins consists of pro-apoptotic proteins, such as Bax and Bad, and anti-apoptotic proteins, including Bcl-2 and Bcl- $X_{L}$ (Gross et al., 1999). The balance between anti-apoptotic and pro-apoptotic $\mathrm{Bcl}-2$ proteins is an important factor in determining whether cells die or survive (Oltvai et al., 1993). Among the Bcl-2 proteins, phosphorylation of Bad at Ser112, Ser136, or Ser155 inactivates pro-apoptotic function by binding to 14-3-3 and dissociating from Bcl-XL (Fang et al., 1999; Harada et al., 1999; Datta et al., 2000). This phosphorylation is mediated by survival signal pathways, including ERKs, Akt, and PKA (Datta et al., 1997; Fang et al., 1999; Harada et al., 1999), which can inhibit c-Myc-induced apoptosis (Kauffmann-Zeh et al., 1997; Weissinger et al., 1997). In addition, caspase proteins, downstream of the $\mathrm{Bcl}-2$ proteins, are key initiators of apoptotic cellular breakdown (Thornberry and Lazebnik, 1998), and cleave poly (ADP-ribose) polymerase (PARP) to induce DNA breakage (Lazebnik et al., 1994). Therefore, it is necessary to examine alterations in the Bcl-2 family network and effectors of apoptosis to elucidate the consequences of changes in c-Myc activity. In this study, we examined changes in C-Myc and $\mathrm{Bcl}-2$ family proteins after repeated ECS to elucidate the effects of ECS on the intracellular apoptotic machinery in the brain.

\section{Materials and Methods}

\section{Preparation of animals and ECS administration}

Animals were treated in accordance with the National Institutes of Health (NIH) Guide for the Care and Use of Laboratory Animals, and formal approval to conduct this experiment has been obtained from the animal subjects review board of Seoul National University Hospital. Male SpragueDawley rats (150-200 g) were housed for 2 weeks before the experiments, and maintained under a $12 \mathrm{~h}$ light/12 $\mathrm{h}$ dark cycle with food and water available ad libitum. The rats were divided into the following four groups: control (sham; $n=8$ ), one ECS (E1X; $n=4)$, five ECSs (E5X; $n=4)$, and ten ECSs (E10X; $n=8)$. The groups were given the following treatments, respectively: sham treatment for 10 days; sham treatment for 9 days and ECS on the tenth day; sham treatment for 5 days and ECS for 5 days; and daily ECS for 10 days. ECS (Medcraft B 24-III, 130 V, 0.5 s; Medcraft, Skippach, PA) was administered via earclip electrodes. The rats were decapitated $24 \mathrm{~h}$ after the last treatment, and their frontal cortices were dissected.

\section{Cell culture}

SH-SY5Y and B35 neuroblastoma cells (ATCC, Manassas, VA) were grown in DMEM (Gibco BRL, Carlsbad, CA) supplemented with 10\% (v/v) FBS and $1 \%$ penicillin-streptomycin (Gibco $\mathrm{BRL}$ ) in a $37^{\circ} \mathrm{C}$ humidified incubator with $5 \% \mathrm{CO}_{2}$.

\section{Immunoblot analysis}

Whole extracts of frontal cortex were used for immunoblot analysis. Frontal cortices were immediately homogenized in a glass-Teflon homogenizer in $10 \% \mathrm{v} / \mathrm{w}$ ice-cold RIPA(+) buffer $(50 \mathrm{mM}$ Tris $[\mathrm{pH}$ 7.4], $150 \mathrm{mM} \mathrm{NaCl}, 1 \%$ Triton, $1 \%$ sodium deoxy- 
cholate, and $0.1 \%$ SDS) containing $1 \mathrm{mM}$ DTT, protease inhibitor cocktail, and $1 \mathrm{mM}$ PMSF (Sigma-Aldrich, St. Louis, MO). After centrifugation at $20,000 \times g$ for $20 \mathrm{~min}$, the supernatants were boiled with Laemmli's sample buffer. Protein concentrations were quantified using a Bio-Rad protein assay kit (Bio-Rad Laboratories, Hercules, CA). Equal quantities of proteins were separated by SDS-PAGE electrophoresis, and transferred to nitrocellulose membranes (Bio-Rad Laboratories). The membranes were blocked with $5 \%$ skimmed milk in TBS-T $(0.1 \%$ Tween 20 in TBS) for $1 \mathrm{~h}$ at room temperature and then incubated overnight at $4^{\circ} \mathrm{C}$ with antibodies against c-Myc, phospho-c-Myc (Thr58/Ser62), caspase-3, PARP (Cell Signaling Technology, Beverley, MA), phospho- c-Myc (Ser62) (GeneTex, San Antonio, TX), phospho-Bad (Ser155), Bcl-2, Bcl-XL, Bax, Bad, 14-3-3ß (Santa Cruz Biotechnology, Santa Cruz, CA), and $\beta$-actin (Sigma-Aldrich), at 1:1,000 dilution. The membranes were then incubated with HRP-conjugated anti-rabbit IgG (Zymed, San Francisco, CA), and signals were detected using an enhanced chemiluminescence system (Pierce, Rockford, IL).

\section{Immunohistochemistry}

For immunohistochemistry, different animals from those in the immunoblotting experiments were used. These rats were treated in the same way except for the methods of analysis. Rats were given repeated ECS for 10 days and were transcardially perfused with saline solution followed by 4\% paraformaldehyde (Sigma-Aldrich) in $10 \mathrm{mM}$ PBS (pH 7.4). Brains were sectioned at $20 \mu \mathrm{m}$ on a freezing microtome (Leitz, Wetzlar, Germany). To perform immunohistochemistry, we used the FR2 area of the frontal cortex (Paxinos and Watson, 1998) (Figure 3), and sections were incubated with antibody against phospho-c-Myc (Thr58/Ser62) at a 1:100 dilution at $4^{\circ} \mathrm{C}$ overnight. $A$ refined avidin-biotin technique in which a biotinylated secondary antibody reacts with several peroxidaseconjugated streptavidin molecules was employed for amplification using a DAKO LSAB+/HRP kit. The sections were incubated in DAB substrate and subsequently mounted with DPX Mountant (Fluka, Buchs, Switzerland).

\section{Double-label immunofluorescence}

The sections were blocked for $1 \mathrm{~h}$ with $3 \%$ BSA in TBST, and incubated with primary antibodies [1:100 anti-phospho-c-Myc (Thr58/Ser62) and 1:100 anti-neuronal nuclear protein (Neu-N; Chemicon, Temecula, CA) or 1:400 anti-glial fibrillary acidic protein (GFAP; Sigma-Aldrich) specific antibodies] at $4{ }^{\circ} \mathrm{C}$ overnight. After washing in TBST, the sections were incubated with secondary antibodies (1:100 Alexa Fluor 488 and 555; Molecular Probes, Eugene, OR) for $1 \mathrm{~h}$ at room temperature. The sections were then fluorescence-labeled, nuclei were stained with 4',6'-diamidino-2-phenylindole (DAPI) (Sigma-Aldrich), mounted with DPX Mountant, and examined by fluorescence microscopy.

\section{Immunoprecipitation}

Tissues were homogenized in RIPA buffer $(50 \mathrm{mM}$ Tris [pH 7.4], $150 \mathrm{mM} \mathrm{NaCl}, 1 \%$ Triton X-100, 0.5\% deoxycholate, $1 \mathrm{mM}$ EGTA, $1 \mathrm{mM}$ EDTA, and Protease Inhibitor Cocktail [Sigma-Aldrich]), and 1 mM PSMF containing $10 \mathrm{mM} \mathrm{N}$-ethylmaleimide as a de-ubiquitinase inhibitor. Pre-cleared samples were immunoprecipitated overnight with anti-ubiquitin (Zymed) or anti-Bad antibody. Immunocomplexes were recovered using protein $A$ or $\mathrm{G}$-agarose and analyzed by immunoblotting using antibodies against phospho-c-Myc (Thr58/Ser62), c-Myc, 14-3-3 $\beta$, and $\mathrm{BCl}-\mathrm{X}_{\mathrm{L}}$.

\section{Data quantification and statistical analysis}

Results are expressed as relative ODs, and are presented as the mean+SEM. The ODs of immunoblot signals were quantified using TINA version 2.10e (Raytest, Straubenhardt, Germany). The mean relative OD of the investigated molecules was compared with the sham control value using analysis of variance, and pairwise comparisons were performed using post hoc Tukey's test. In addition, an independent $t$-test was performed to compare the mean relative ODs of $\mathrm{Bcl}-2$, Bcl- $\mathrm{X}_{\mathrm{L}}, \mathrm{Bax}$, and Bad between the sham control and E10X groups. Level of significance was set at $P<0.05$. All tests were performed using SPSS 12.0 for Windows (SPSS, Chicago, IL).

\section{Results}

\section{Repeated ECS decreases c-Myc and increases phosphorylation of Thr58-c-Myc in the rat frontal cortex}

The total amount of c-Myc was significantly affected by repeated ECS administration $(F=34.78, d f=3$, $P<0.01)$. In the $\mathrm{E} 10 \mathrm{X}$ group, the immunoreactivity of total c-Myc was significantly reduced compared to that in the sham group $(F=34.78$, df $=3, P<0.01)$. However, the immunoreactivity of total c-Myc in the E1X and E5X groups did not significantly change compared to that in the sham 
group $(\mathrm{F}=34.78, \mathrm{df}=3, P=0.91$ and $P=0.38$, respectively; Figure 1). The immunoreactivity of phospho-c-Myc (Thr58/Ser62) showed a significant difference over the course of repeated ECS in the rat frontal cortex $(\mathrm{F}=132.28, \mathrm{df}=3, P<0.01)$. Phosphorylation of c-Myc, detected with antibodies specific to phosphorylated Thr58 and Ser62 residues, increased $24 \mathrm{~h}$ after single ECS, and further increased in the E5X and E10X groups, with a significant difference between the sham and E5X and $E 10 X$ groups ( $F=132.28$, df $=3, P<0.01$ for both groups). The increased level of c-Myc phosphorylation at the Thr58 or Ser62 residues showed a linear trend as the number of administered ECSs increased. To determine whether this increase in phosphorylation occurred at Thr58 or Ser62, the same samples were immunoblotted with a specific antibody against phospho-Ser62c-Myc. There was no immunoreactivity detected with anti-phospho-Ser62-c-Myc antibody (Figure 1).

\section{Increased ubiquitination of c-Myc and phosphorylated c-Myc in response to repeated ECS}

The phosphorylation of c-Myc at the Thr58 residue has been reported to be associated with ubiquitination-mediated proteasomal degradation of c-Myc (Gregory et al., 2003; Yeh et al., 2004). Therefore, we expected the reduction in the total amount of c-Myc, with increased phosphorylation of Thr58-cMyc, to be related to the ubiquitination of c-Myc in response to repeated ECS. To determine whether ubiquitination was involved in down-regulation of

A

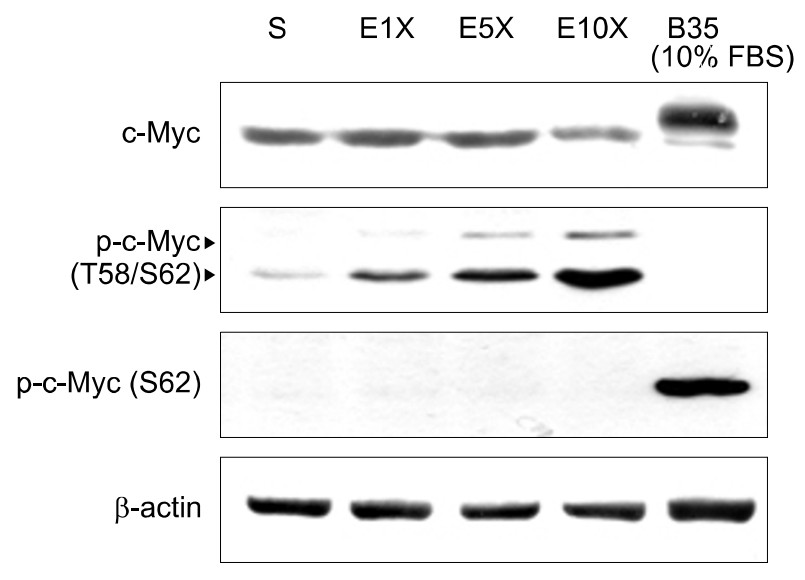

B
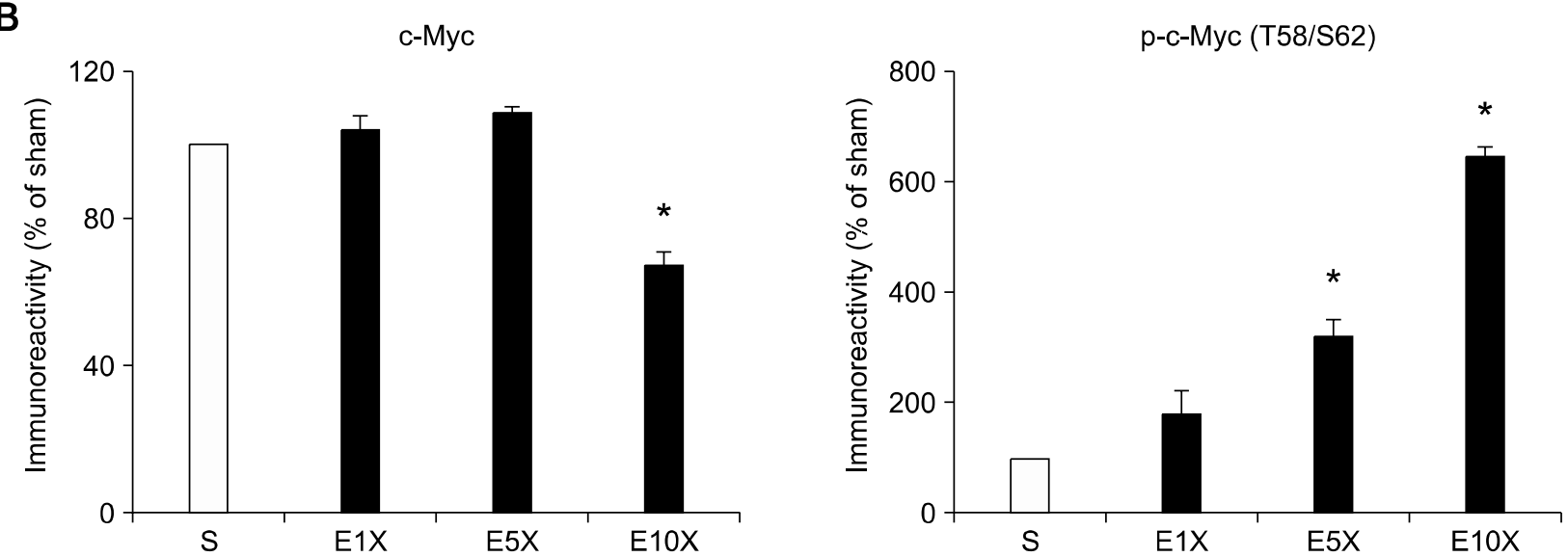

Figure 1. Increased phosphorylation of c-Myc at Thr58, and reduction in the amount of total c-Myc in the rat frontal cortex induced by repeated ECS. (A) Protein samples from the frontal cortex were immunoblotted with antibodies against phospho-c-Myc (Thr58/Ser62), phospho-c-Myc (Ser62), c-Myc, and $\beta$-actin. As a control, B35 rat neuroblastoma cells were stimulated with $10 \% \mathrm{FBS}$, and cell samples were immunoblotted with the same antibodies. (B) To quantify the immunoblotting results, data are expressed as relative ODs, and are represented as the mean + SEM (S and E10X: $n=8$ per each group, E1X and E5X: $n=4$ per each group). Relative ODs are quoted as percentages versus the ODs of the sham control group. $S$ indicates the sham-treated control. * Significant differences between the OD of the ECS treatment group and that of the sham control group $(P<0.05)$. 
c-Myc, proteins were immunoprecipitated with the ubiquitin antibody, and then immunoblotted using antibodies against c-Myc and phospho-Thr58/ Ser62-c-Myc. Both ubiquitination of phospho-Thr58/ Ser62-c-Myc and total c-Myc increased in the E10X group, compared to that in the sham group (Figure 2).

\section{Phosphorylated c-Myc is localized in neuronal cells}

Immunohistochemical analysis was conducted on the frontal cortical tissues to confirm the immunoblot findings. Increased immunoreactivity with anti-phospho-c-Myc (Thr58/Ser62) antibody was observed in the E10X group. The number of cells densely stained for phospho-c-Myc (Thr58/Ser62) was higher in the E10X than in the sham control group (Figure 3A). Next, we performed double-label immunofluorescence analysis to investigate whether the cells stained with phospho-c-Myc (Thr58/Ser62) antibody were of neuronal or glial origin. Immunoreactivity of phospho-c-Myc was co-localized with

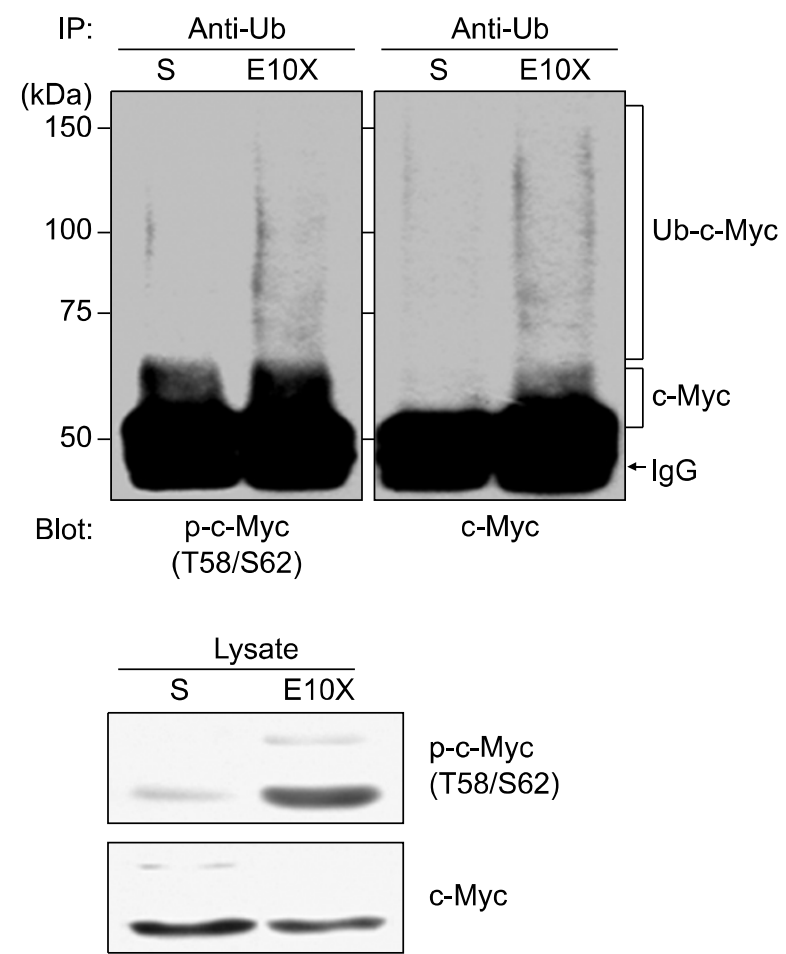

Figure 2. Increased ubiquitination of c-Myc and phospho-c-Myc in the rat frontal cortex after repeated ECS for 10 days. To detect ubiquitinated protein, tissue extracts were immunoprecipitated with anti-ubiquitin antibody, and analyzed by immunoblotting with anti-c-Myc and anti-phospho-c-Myc antibodies. Increased ubiquitination of C-Myc and phospho-c-Myc (Thr58/Ser62) was found in the E10X group compared to that in the sham group. $S$ indicates the sham-treated control. Results shown are representative of four independent experiments with similar results.
Neu-N and DAPI immunoreactivity, but not with GFAP immunoreactivity (Figure 3B). Repeated ECS was demonstrated to increase the phosphorylation of Thr58-c-Myc in the nucleus of neurons in the rat frontal cortex.

\section{Effects of ECS on the Bcl-2 family of proteins}

It was speculated that the down-regulation of c-Myc may represent the anti-apoptotic activity of neurons exerted by repeated ECS in the rat frontal cortex. $\mathrm{Bcl}-2$ proteins play important roles in induction of cellular apoptosis in relation to c-Myc, directly or indirectly (Nilsson and Cleveland, 2003). Therefore, to determine the consequence of down-regulating $\mathrm{c}-\mathrm{Myc}$, the changes in the $\mathrm{Bcl}-2$ proteins were investigated following repeated ECS. After ECS administration, the immunoreactivity of pro-survival proteins $\mathrm{Bcl}-2$ and $\mathrm{Bcl}-\mathrm{X}_{\mathrm{L}}$, and pro-apoptotic proteins Bax and Bad, was not altered in the rat frontal cortex. In addition, the Bax/Bcl-2 ratio, known as an indicator of susceptibility to apoptosis (Oltvai et al., 1993), also did not change significantly after repeated ECS for 10 days (Figure $4 A$ and $5 A$ ). The immunoreactivity of PARP, and cleaved PARP and caspase-3, effector molecules of the apoptotic process, also did not change (Figure 4B).

\section{ECS increases phosphorylation of Ser155-Bad and binding of Bad to 14-3-3}

Among the $\mathrm{Bcl}-2$ family of proteins, pro-apoptotic activity of Bad is regulated by phosphorylation. In particular, phosphorylation of BAD at the Ser155 residue inactivates $\mathrm{Bad}$ by stabilizing its binding to 14-3-3, and dissociation from Bcl- $\mathrm{X}_{\mathrm{L}}$ (Datta et al., 2000). We found that immu noreactivity of phospho- Ser155-Bad significantly increased after repeated ECS for 10 days ( $P<0.01$; Figure 5A). Tissue samples were immunoprecipitated with anti-Bad antibody, followed by immunoblotting with anti-14- 3-3 and anti-Bcl- $X_{L}$ antibodies. The amount of 14-3-3 bound to Bad was significantly elevated at $24 \mathrm{~h}$ after ten daily ECS. However, there was no binding of Bad and Bcl- $\mathrm{X}_{\mathrm{L}}$ at $24 \mathrm{~h}$ in either the sham control or E10X groups (Figure 5B).

\section{Discussion}

Our most important finding is that repeated ECS induced the down-regulation of c-Myc via ubiquitination, and the inactivation of Bad by increasing binding with 14-3-3 protein in the rat frontal cortex. Increased phosphorylation at the Thr58 residue 
A
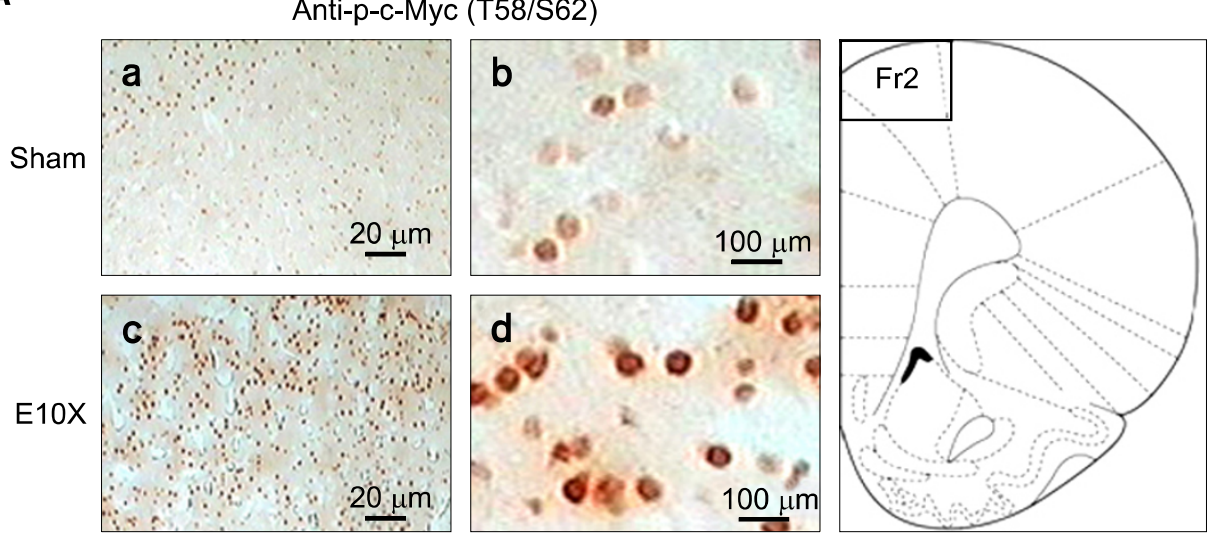

B

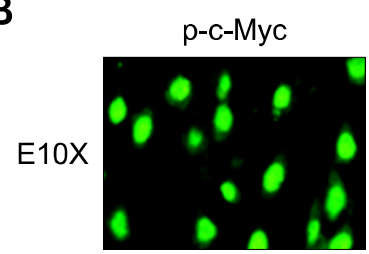

p-c-Myc

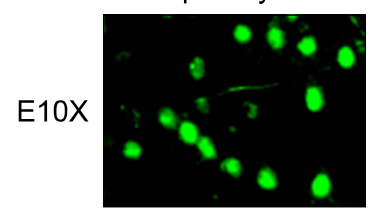

Neu-N

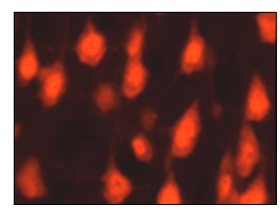

GFAP

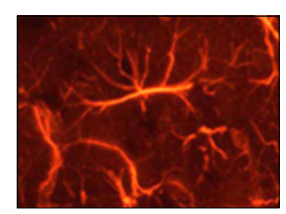

DAPI

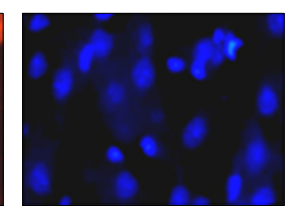

DAPI

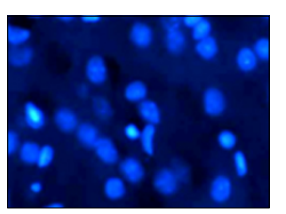

Overlay

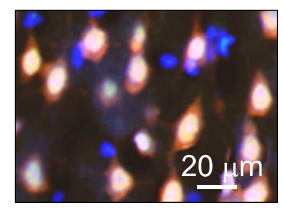

Overlay

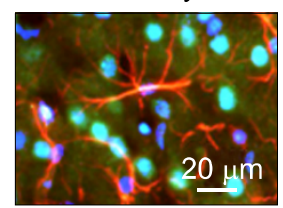

Figure 3. Increased immunostaining of phospho-c-Myc co-localized with immunofluorescence of Neu-N and DAPI in the rat frontal cortex after repeated ECS for 10 days. (A) Representative microscopic images taken from sections stained for phospho-c-Myc (Thr58/Ser62). All captured images were obtained $24 \mathrm{~h}$ after repeated sham $(a, b)$ or ECS treatments $(c, d)$ for 10 days. The number of cells immunostained for phospho-c-Myc (Thr58/Ser62) was higher in the E10X group than in the sham group. Magnification bar $=$ $100 \mu \mathrm{m}$ in $\mathrm{a}$ and $\mathrm{d}$, and $20 \mu \mathrm{m}$ in b and $d$. (B) Double-label immunofluorescence analysis was performed to determine whether the cells stained for phospho-c-Myc (Thr58/Ser62) antibody were of neuronal or glial origin. Immunofluorescence of phospho-c-Myc was co-localized with that of Neu-N and DAPI, but not with that of GFAP. Magnification bar $=20 \mu \mathrm{m}$. and ubiquitination of c-Myc with a reduction in the total amount of c-Myc in response to repeated ECS suggests that ECS may reduce c-Myc protein levels via the ubiquitination-proteasomal degradation process. The protein levels of $\mathrm{Bcl}-2$, Bcl- $\mathrm{X}_{\mathrm{L}}$, Bax, and Bad showed no change. However, phosphorylation of Bad at Ser-155 and binding of Bad to 14-3-3 increased without binding with $\mathrm{Bcl}-\mathrm{X}_{\mathrm{L}}$, which implies that repeated ECS administration elicits pro-survival and anti-apoptotic activity in the rat frontal cortex. Taken together, the results provide further evidence of the trophic effects of repeated ECS to inactivate apoptosis via down-regulation of c-Myc and inactivation of Bad.

Phosphorylation of c-Myc at the Ser62 or Thr58 residue is an important posttranslational modification mechanism to determine the stability of c-Myc (Yeh et al., 2004). This phosphorylation is mediated by Ras-dependent signaling pathways, including ERK, Akt, and glycogen synthase kinase-3 $\beta$ (Gregory et al., 2003; Yeh et al., 2004; Vervoorts et al., 2006). In this study, phosphorylation of c-Myc increased after repeated ECS treatment, using antibodydetecting phosphorylation at either the Ser62 or Thr58 residue. However, when the same samples were immunoblotted with antibodies specific to the Ser62 residue only, no immunoreactivity was detected. Therefore, we concluded that the phosphorylation signal emanated exclusively from Thr58. Phosphorylation of c-Myc at Thr58 has been reported to promote c-Myc dephosphorylation at Ser62, and facilitate c-Myc degradation by the ubiquitinmediated proteasome pathway (Gregory et al., 2003; Yeh et al., 2004; Vervoorts et al., 2006). In the present study, ten daily repeated ECSs significantly reduced the immunoreactivity of total c-Myc. This was accompanied by increased ubiquitination of c-Myc and phosphorylated c-Myc. Repeated ECSs seem to promote degradation of c-Myc via increased phosphorylation at the Thr58 residue, and ubiquitination of c-Myc.

Despite the role of c-Myc promoting cell proliferation, growth, and differentiation, it can also trigger apoptosis (Nilsson and Cleveland, 2003). These contrasting findings imply that c-Myc can induce different effects depending on cellular factors, such as cell type and intracellular or extracellular cues. (Nakagomi et al., 1996; Rogulski et al., 2005). In post-mitotic neurons, c-Myc plays a critical role in promoting apoptosis. For example, quinolinic acid 
A
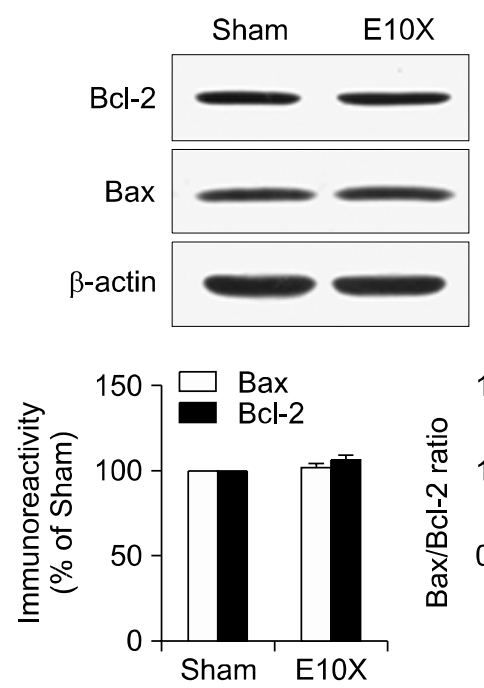

B

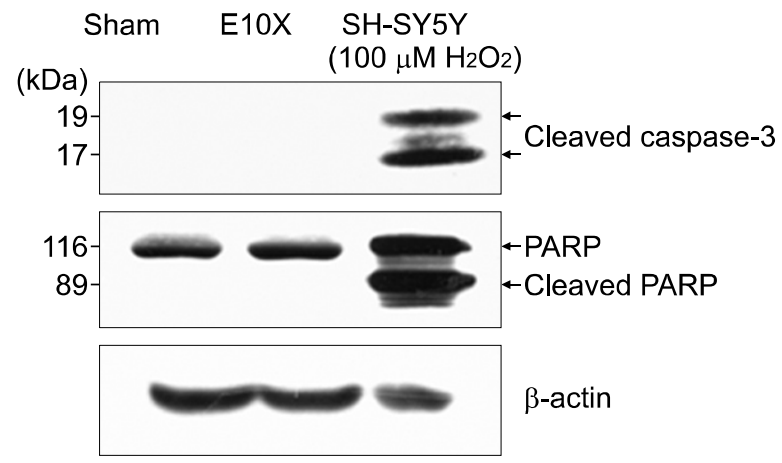

Figure 4. No changes in immunoreactivity of Bcl-2 and Bax, and cleavage of caspase-3 and PARP in the rat frontal cortex after repeated ECS for 10 days. (A) Protein samples were immunoblotted with antibodies against Bcl-2, Bax, and $\beta$-actin. Quantification of immunoblot data by densitometry and comparison were performed as described in the legend to Figure 1 ( $n=8$ per each treatment group). In addition, the ratio of the relative ODs of Bax and $\mathrm{Bcl}-2$ was compared between the sham control and E10X groups. There were no changes in the immunoreactivity of Bax and Bcl-2, or the Bax/Bcl-2 ratio. (B) There was no immunoreactivity detected by antibodies against cleaved caspase- 3 and cleaved PARP in the extracts of the frontal cortex from the sham control and E10X groups. Immunoreactivity of PARP showed no change in the E10X group compared to the sham control group. As a positive control, SH-SY5Y cells were stimulated with $100 \mu \mathrm{M} \mathrm{H}_{2} \mathrm{O}_{2}$ for $24 \mathrm{~h}$, and cell samples were immunoblotted with the same antibodies. Results shown are representative of four independent experiments with similar results.

and kainic acid promote induction of c-Myc and p53, with subsequent apoptosis in striatal neurons (Qin et al., 1999; Nakai et al., 2000; Liang et al., 2005). In contrast to the induction of c-Myc by excitotoxic stimuli, we found that the total amount of c-Myc decreased in the rat frontal cortex after repeated ECS. Pre-exposure to repeated ECS may attenuate the neuronal cell death triggered by kainic acid-evoked status epilepticus (Kondratyev et al., 2001). These findings imply that repeated ECS elicits an anti-apoptotic effect via downregulation of $\mathrm{c}-\mathrm{Myc}$, and this is related to the therapeutic and protective effect of ECS, but not to the seizure activity which is a common phenomenon induced by excitotoxic stimuli and ECS.

To investigate the influence of down-regulation of c-Myc on the molecules related to the apoptotic machinery, we examined the changes in apoptosisrelated proteins, such as the $\mathrm{Bcl}-2$ family of proteins, caspase, and PARP. Bax cooperates with c-Myc to induce apoptosis (Mitchell et al., 2000). Bcl-2 or $\mathrm{Bcl}-\mathrm{X}_{\mathrm{L}}$ inhibits C-Myc-induced apoptosis, and C-Myc suppresses the expression of $\mathrm{Bcl}-2$ and $\mathrm{Bcl}-\mathrm{X}_{\mathrm{L}}$ (Pelengaris et al., 2002; Maclean et al., 2003). In this study, there were no changes in the immunoreactivity of $\mathrm{Bcl}-2, \mathrm{Bcl}-\mathrm{XL}$, Bax, and $\mathrm{Bad}$ and the Bax/Bcl-2 ratio, an important determinant of susceptibility to neuronal apoptosis (Oltvai et al., 1993;
Zha et al., 1996) in response to repeated ECS. In addition, the amount and cleavage of caspase-3 and PARP showed no change after ECS administration. These findings suggest that repeated ECS does not increase vulnerability to apoptosis in the rat frontal cortex.

Phosphorylation of Bad at either a single Ser112, Ser136, or Ser155, or at multiple sites can contribute to inactivation of the apoptotic function of Bad (Datta et al., 1997; Fang et al., 1999; Harada et al., 1999). Among the phosphorylation sites involved in blocking the apoptotic activity of Bad, Ser155 phosphorylation of Bad may be critical to cell survival (Datta et al., 2000). Survival signals may block apoptosis by phosphorylating the pro-apoptotic Bad at Ser155 (Datta et al., 2000). Within multiple kinases involved in the phosphorylation of Bad at Ser155, PKA directly phosphorylates Bad at Ser155, and $A$ kinase anchoring protein (AKAP) induces PKA targeting to the mitochondria to phosphorylate Bad (Harada et al., 1999). Ribosomal s6 kinase1 (RSK1) may also stimulate phosphorylation of Bad at Ser155 and rescue Bad-mediated cell death (Tan et al., 2000). Repeated ECS affects PKA signal pathway (Altar et al., 2004), AKAP expression (Lee et al., 2004), and RSK1 phosphorylation (Kang et al., 2006) in the rat brain. Therefore, Bad phosphorylation may change after repeated ECS. 
A

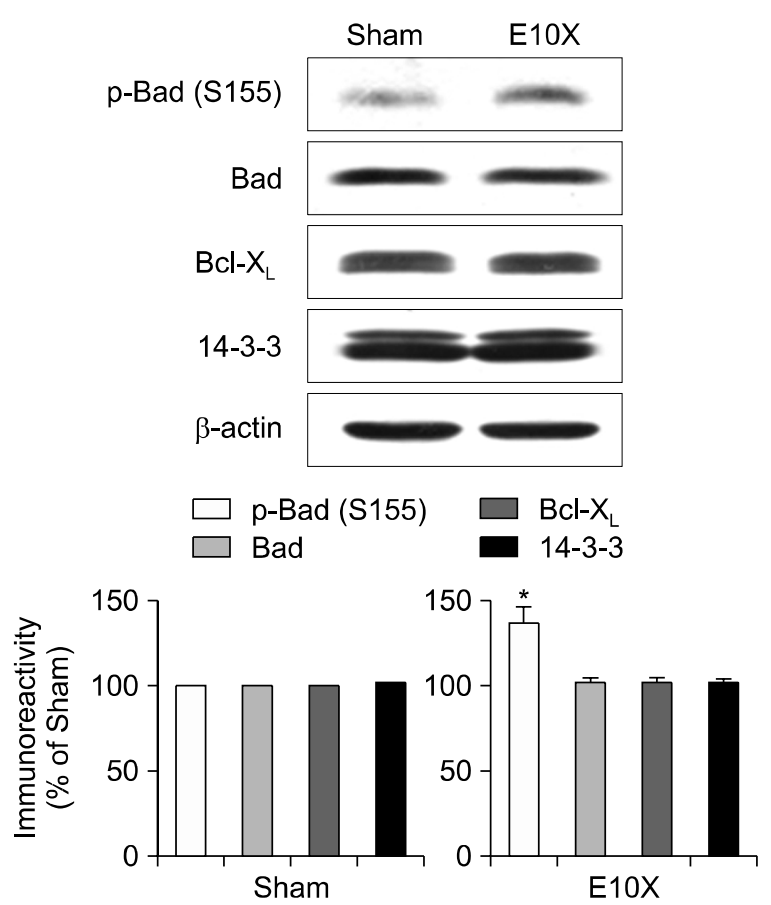

B

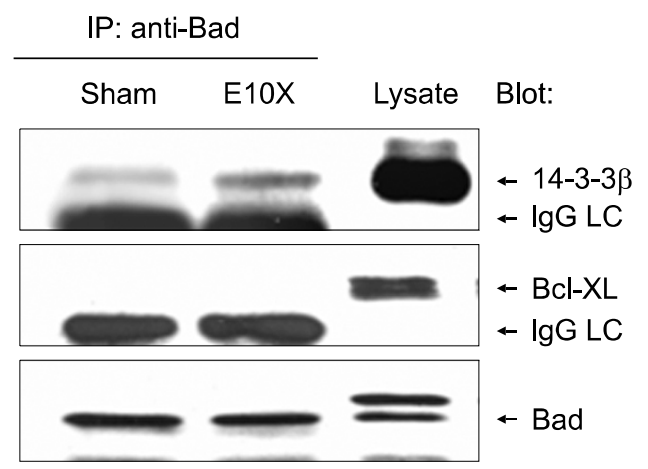

Figure 5. Increased phosphorylation of Bad at Ser155 and increased binding of Bad to 14-3-3 in the rat frontal cortex after repeated ECS treatments for 10 days. (A) Immunoblotting of the rat frontal cortex after repeated ECS treatment for 10 days was performed with antibodies against Bad, Bcl- $X_{L}, 14-3-3$, and phospho-Ser155-Bad. Quantification of immunoblotting data by densitometry and comparison was performed as described in the legend to Figure 1 ( $n=8$ per each treatment group). Immunoreactivity of phosphorylation of Bad at Ser155 significantly increased after repeated ECS. However, immunoreactivity of total Bad, Bcl- $X_{L}$, and 14-3-3 did not show any significant difference between the sham control and E10X groups. (B) To determine the binding of Bad to 14-3-3 or Bcl- $X_{L}$, tissue extracts were immunoprecipitated with anti-Bad antibody, and then immunoblotted with anti-14-3-3 and anti-Bcl- $X_{L}$ antibodies. Binding of Bad to 14-3-3 increased in the E10X group compared to the sham control group. However, binding of Bad to Bcl- $X_{L}$ was not evident in either the sham control or E10X groups. Results shown are representative of four independent experiments with similar results.

In fact, repeated ECSs were found to increase phosphorylation of Bad at Ser155 in the rat frontal cortex. The phosphorylation of Bad at Ser-155 stabilizes the binding of Bad to 14-3-3 scaffold protein, and promotes dissociation from $\mathrm{Bcl}-\mathrm{X}_{\mathrm{L}}$, which may be a critical mechanism for cell survival (Datta et al., 2000). In this study, the binding of Bad to 14-3-3 increased, accompanied by an upregulated phosphorylation level of Bad at Ser155, after ten daily ECSs, compared to that in the sham control group; the binding of Bad with $\mathrm{Bcl}-\mathrm{X}_{\mathrm{L}}$ was absent in both the sham control and E10X groups. These findings suggest that the pro-apoptotic activity of Bad was blocked by binding to the 14-3-3 protein, but the pro-survival activity of $\mathrm{Bcl}-\mathrm{X}_{\mathrm{L}}$ was not interrupted during the course of repeated ECSs. Thus, repeated ECSs may be trophic stimuli that enhance survival signal activity in neural cells because survival factors inhibit apoptosis by blocking Bad activity.

In summary, repeated ECSs induced downregulation of c-Myc via ubiquitination-mediated degradation and Bad phosphorylation at Ser155, with increased binding to 14-3-3 in the rat frontal cortex without enhancing susceptibility to apoptosis. These findings suggest that repeated ECS inactivates the apoptotic machinery to exert its protective activities, and c-Myc and Bad may play an important role in the therapeutic action of ECT, in agreement with previous reports demonstrating that ECS elicits trophic action in the brain (Kondratyev et al., 2001; Hellsten et al., 2002; Kim et al., 2005; Madsen et al., 2005; Busnello et al., 2006; Wennstrom et al., 2006). In conclusion, the present findings further support the neuroprotective effect of ECS, and facilitate our understanding of the mechanism of action of ECT as a neurotrophic stimulus.

\section{Acknowledgments}

This research was supported by the Korea Research Foundation Grant funded by the Korean Government (MOEHRD) (KRF-2005-015-E00147) and by a grant (No. M103KV010013-07K2201-01310) from the Brain Research Center of the 21st Century Frontier Research Program funded by the Ministry of Science and Technology, Republic of Korea. Yong Sik Kim and Se Hyun Kim were supported by 
the second stage Brain Korea 21 Project in 2006.

\section{References}

Akiyama K, Kanzaki A, Tsuchida K, Ujike H. Methamphetamine-induced behavioral sensitization and its implications for relapse of schizophrenia. Schizophr Res 1994; $12: 251-7$

Altar CA, Laeng P, Jurata LW, Brockman JA, Lemire A, Bullard J, Bukhman YV, Young TA, Charles V, Palfreyman MG. Electroconvulsive seizures regulate gene expression of distinct neurotrophic signaling pathways. J Neurosci 2004; 24:2667-77

Benes FM, Matzilevich D, Burke RE, Walsh J. The expression of proapoptosis genes is increased in bipolar disorder, but not in schizophrenia. Mol Psychiatry 2006;11:241-51

Busnello JV, Leke R, Oses JP, Feier G, Bruch R, Quevedo J, Kapczinski F, Souza DO, Cruz Portela LV. Acute and chronic electroconvulsive shock in rats: effects on peripheral markers of neuronal injury and glial activity. Life Sci 2006;78:3013-7

Datta SR, Dudek H, Tao X, Masters S, Fu H, Gotoh Y, Greenberg ME. Akt phosphorylation of BAD couples survival signals to the cell-intrinsic death machinery. Cell 1997;91: 231-41

Datta SR, Katsov A, Hu L, Petros A, Fesik SW, Yaffe MB, Greenberg ME. 14-3-3 proteins and survival kinases cooperate to inactivate BAD by $\mathrm{BH} 3$ domain phosphorylation. Mol Cell 2000;6:41-51

Fang X, Yu S, Eder A, Mao M, Bast RC Jr, Boyd D, Mills GB. Regulation of BAD phosphorylation at serine 112 by the Ras-mitogen-activated protein kinase pathway. Oncogene 1999;18:6635-40

Gregory MA, Qi Y, Hann SR. Phosphorylation by glycogen synthase kinase- 3 controls c-myc proteolysis and subnuclear localization. J Biol Chem 2003;278:51606-12

Gross A, McDonnell JM, Korsmeyer SJ. BCL-2 family members and the mitochondria in apoptosis. Genes Dev 1999;13:1899-911

Harada H, Becknell B, Wilm M, Mann M, Huang LJ, Taylor SS, Scott JD, Korsmeyer SJ. Phosphorylation and inactivation of BAD by mitochondria-anchored protein kinase A. Mol Cell 1999;3:413-22

Hellsten J, Wennstrom M, Mohapel P, Ekdahl CT, Bengzon $\mathrm{J}$, Tingstrom A. Electroconvulsive seizures increase hippocampal neurogenesis after chronic corticosterone treatment. Eur J Neurosci 2002;16:283-90

Jarskog LF. Apoptosis in schizophrenia: pathophysiologic and therapeutic considerations. Curr Opin Psychiatry 2006; 19:307-12

Kang UG, Hong KS, Jung HY, Kim YS, Seong YS, Yang YC, Park JB. Activation and tyrosine phosphorylation of $44-\mathrm{kDa}$ mitogen-activated protein kinase (MAPK) induced by electroconvulsive shock in rat hippocampus. J Neurochem 1994;63:1979-82
Kang UG, Roh MS, Jung JR, Shin SY, Lee YH, Park JB, Kim YS. Activation of protein kinase $B$ (Akt) signaling after electroconvulsive shock in the rat hippocampus. Prog Neuropsychopharmacol Biol Psychiatry 2004;28:41-4

Kang UG, Koo YJ, Jeon WJ, Park DB, Juhnn YS, Park JB, $\mathrm{Kim}$ YS. Activation of extracellular signal-regulated kinase signaling by chronic electroconvulsive shock in the rat frontal cortex. Psychiatry Res 2006;145:75-8

Kauffmann-Zeh A, Rodriguez-Viciana P, Ulrich E, Gilbert C, Coffer P, Downward J, Evan G. Suppression of C-Mycinduced apoptosis by Ras signalling through $\mathrm{PI}(3) \mathrm{K}$ and PKB. Nature 1997;385:544-8

Kim Y, Seo MS, Kang UG, Yoon SC, Ahn YM, Kim YS, Juhnn YS. Activation of Cdk2-pRB-E2F1 cell cycle pathway by repeated electroconvulsive shock in the rat frontal cortex. Biol Psychiatry 2005;57:107-9

Kondratyev A, Sahibzada N, Gale K. Electroconvulsive shock exposure prevents neuronal apoptosis after kainic acidevoked status epilepticus. Brain Res Mol Brain Res 2001; 91:1-13

Lazebnik YA, Kaufmann SH, Desnoyers S, Poirier GG, Earnshaw WC. Cleavage of poly (ADP-ribose) polymerase by a proteinase with properties like ICE. Nature 1994;371: 346-47

Lee YI, Koo YJ, Cho CH, Seo M, Kang UG, Kim YS, Juhnn $Y S$. Repeated electroconvulsive shock treatment increases the expression of $A$ kinase anchoring proteins in the rat hippocampus. Neurosci Lett 2004;355:213-6

Liang ZQ, Wang XX, Wang Y, Chuang DM, DiFiglia M, Chase TN, Qin ZH. Susceptibility of striatal neurons to excitotoxic injury correlates with basal levels of $\mathrm{Bcl}-2$ and the induction of P53 and c-Myc immunoreactivity. Neurobiol Dis 2005; 20:562-73

Maclean KH, Keller UB, Rodriguez-Galindo C, Nilsson JA, Cleveland JL. c-Myc augments gamma irradiation-induced apoptosis by suppressing Bcl-XL. Mol Cell Biol 2003;23: 7256-70

Madsen TM, Yeh DD, Valentine GW, Duman RS. Electroconvulsive seizure treatment increases cell proliferation in rat frontal cortex. Neuropsychopharmacology 2005;30: 27-34

McGahan L, Hakim AM, Robertson GS. Hippocampal Myc and p53 expression following transient global ischemia. Brain Res Mol Brain Res 1998;56:133-45

Mitchell KO, Ricci MS, Miyashita T, Dicker DT, Jin Z, Reed JC, El-Deiry WS. Bax is a transcriptional target and mediator of c-myc-induced apoptosis. Cancer Res 2000;60:6318-25

Nakagomi T, Asai A, Kanemitsu H, Narita K, Kuchino Y, Tamura A, Kirino T. Up-regulation of c-myc gene expression following focal ischemia in the rat brain. Neurol Res 1996;18:559-63

Nakai M, Qin ZH, Chen JF, Wang Y, Chase TN. Kainic acid-induced apoptosis in rat striatum is associated with nuclear factor-kappaB activation. J Neurochem 2000;74: $647-58$ 
Newton SS, Collier EF, Hunsberger J, Adams D, Terwilliger $R$, Selvanayagam E, Duman RS. Gene profile of electroconvulsive seizures: induction of neurotrophic and angiogenic factors. J Neurosci 2003;23:10841-51

Nibuya M, Morinobu S, Duman RS. Regulation of BDNF and trkB mRNA in rat brain by chronic electroconvulsive seizure and antidepressant drug treatments. J Neurosci 1995;15: 7539-47

Nilsson JA, Cleveland JL. Myc pathways provoking cell suicide and cancer. Oncogene 2003;22:9007-21

Oltvai ZN, Milliman CL, Korsmeyer SJ. Bcl-2 heterodimerizes in vivo with a conserved homolog, Bax, that accelerates programmed cell death. Cell 1993;74:609-19

Paxinos G, Watson C. The rat brain in stereotactic coordinates, 4th Ed, 1998, Academic Press, Sydney, Australia

Pelengaris S, Khan M, Evan GI. Suppression of Myc-induced apoptosis in beta cells exposes multiple oncogenic properties of Myc and triggers carcinogenic progression. Cell 2002;109:321-34

Pulverer BJ, Fisher C, Vousden K, Littlewood T, Evan G, Woodgett JR. Site-specific modulation of c-Myc cotransformation by residues phosphorylated in vivo. Oncogene 1994;9:59-70

Qin ZH, Chen RW, Wang Y, Nakai M, Chuang DM, Chase TN. Nuclear factor kappaB nuclear translocation upregulates c-Myc and p53 expression during NMDA receptor-mediated apoptosis in rat striatum. J Neurosci 1999;19:4023-33

Raff MC, Barres BA, Burne JF, Coles HS, Ishizaki Y, Jacobson MD. Programmed cell death and the control of cell survival: lessons from the nervous system. Science 1993;262:695-700

Rogulski K, Li Y, Rothermund K, Pu L, Watkins S, Yi F, Prochownik EV. Onzin, a c-Myc-repressed target, promotes survival and transformation by modulating the Akt-Mdm2p53 pathway. Oncogene 2005;24:7524-41

Tan Y, Demeter MR, Ruan H, Comb MJ. BAD Ser-155 phosphorylation regulates $\mathrm{BAD} / \mathrm{Bcl}-\mathrm{XL}$ interaction and cell survival. J Biol Chem 2000;275:25865-9

Thiriet N, Jayanthi S, McCoy M, Ladenheim B, Lud Cadet J. Methamphetamine increases expression of the apoptotic C-myc and L-myc genes in the mouse brain. Brain Res Mol Brain Res 2001;90:202-4

Thornberry NA, Lazebnik Y. Caspases: enemies within. Science 1998;281:1312-6

Vervoorts J, Lüscher-Firzlaff J, Lüscher B. The ins and outs of MYC regulation by posttranslational mechanisms. J Biol Chem 2006;281:34725-9

Weissinger EM, Eissner G, Grammer C, Fackler S, Haefner B, Yoon LS, Lu KS, Bazarov A, Sedivy JM, Mischak H, Kolch W. Inhibition of the Raf-1 kinase by cyclic AMP agonists causes apoptosis of v-abl-transformed cells. Mol Cell Biol 1997; $17: 3229-41$

Wennstrom M, Hellsten J, Ekstrand J, Lindgren $\mathrm{H}$, Tingstrom A. Corticosterone-induced inhibition of gliogenesis in rat hippocampus is counteracted by electroconvulsive seizures. Biol Psychiatry 2006;59:178-86

Yeh E, Cunningham M, Arnold H, Chasse D, Monteith T, Ivaldi G, Hahn WC, Stukenberg PT, Shenolikar S, Uchida T, Counter CM, Nevins JR, Means AR, Sears R. A signalling pathway controlling C-Myc degradation that impacts oncogenic transformation of human cells. Nat Cell Biol 2004;6:308-18

Zha J, Harada H, Yang E, Jockel J, Korsmeyer SJ. Serine phosphorylation of death agonist BAD in response to survival factor results in binding to $14-3-3$ not $B C L-X(L)$. Cell 1996;87:619-28 